Article

\title{
Copy Number Analysis of 24 Oncogenes: MDM4 Identified as a Putative Marker for Low Recurrence Risk in Non Muscle Invasive Bladder Cancer
}

\author{
Samanta Salvi ${ }^{1}$, Daniele Calistri ${ }^{1}$, Giorgia Gurioli ${ }^{1}$, Elisa Carretta ${ }^{2}$, Luigi Serra ${ }^{3}$, \\ Roberta Gunelli $^{4}$, Wainer Zoli ${ }^{1, *}$ and Valentina Casadio ${ }^{1}$
}

1 Biosciences Laboratory, Istituto Scientifico Romagnolo per lo Studio e la Cura dei Tumori (IRST) IRCCS, Meldola 47014, Italy; E-Mails: samanta.salvi@irst.emr.it (S.S.); daniele.calistri@irst.emr.it (D.C.); giorgia.gurioli@irst.emr.it (G.G.); valentina.casadio@irst.emr.it (V.C.)

2 Unit of Biostatistics and Clinical Trials, Istituto Scientifico Romagnolo per lo Studio e la Cura dei Tumori (IRST) IRCCS, Meldola 47014, Italy; E-Mail: elisa.carretta@irst.emr.it

3 Pathology Unit, Morgagni Pierantoni Hospital, Forlì 47121, Italy; E-Mail: 1.serra@ausl.fo.it

4 Department of Urology, Morgagni Pierantoni Hospital, Forli 47121, Italy; E-Mail: fiorifo@tin.it

* Author to whom correspondence should addressed; E-Mail: wainer.zoli@irst.emr.it; Tel.: +39-0543-739263; Fax: +39-0543-739221.

Received: 25 March 2014; in revised form: 26 June 2014 / Accepted: 4 July 2014 / Published: 14 July 2014

Abstract: Patients with non-muscle invasive bladder cancer (NMIBC) generally have a high risk of relapsing locally after primary tumor resection. The search for new predictive markers of local recurrence thus represents an important goal for the management of this disease. We studied the copy number variations (CNVs) of 24 oncogenes (MDM4, MYCN, ALK, PDGFRA, KIT, KDR, DHFR, EGFR, MET, SMO, FGFR1, MYC, ABL1, RET, CCND1, CCND2, CDK4, MDM2, AURKB, ERBB2, TOP2A, AURKA, AR and BRAF) using multiplex ligation probe amplification technique to verify their role as predictive markers of recurrence. Formalin-fixed paraffin-embedded tissue samples from 43 patients who underwent transurethral resection of the bladder (TURB) were used; 23 patients had relapsed and 20 were disease-free after 5 years. Amplification frequencies were analyzed for all genes and MDM4 was the only gene that showed significantly higher amplification in non recurrent patients than in recurrent ones (0.65 vs. 0.3; Fisher's test $p=0.023)$. Recurrence-free survival analysis confirmed the predictive role of MDM4 (log-rank test $p=0.041$ ). Our preliminary results indicate a putative role for the MDM4 gene in 
predicting local recurrence of bladder cancer. Confirmation of this hypothesis is needed in a larger cohort of NMIBC patients.

Keywords: NMIBC; recurrence; multiplex ligation probe amplification (MLPA); MDM4

\section{Introduction}

Bladder cancer is the 11th most common tumor worldwide [1]. The majority of cases present as non muscle invasive bladder cancers (NMIBC), which have a good long-term prognosis and low risk of progression and death. However, after initial transurethral bladder resection (TURB), about $80 \%$ of patients with NMIBC experience local recurrence within 5 years. The standard follow up of NMIBC involves a high number of cystoscopies, with consequently high healthcare costs and, often, low patient compliance [2].

Multiplicity, tumor size and prior relapse rate are the only recurrence-related parameters currently available for monitoring patients with bladder cancer [2]. However, this information would not seem to be accurate enough to ensure an adequate follow-up of individuals with stage Ta-T1 disease. There are four main mechanisms by which recurrence may occur: incomplete resection, tumor cell re-implantation, growth of microscopic tumors and new tumor formation [3]. The first two mechanisms are surgery related and can be avoided, while the growth of microscopic tumors or new tumor formation may be due to specific molecular alterations in urothelial cells. It would thus be useful to understand whether these molecular changes can be used to predict local bladder cancer recurrence.

Urothelial cancer is a heterogeneous disease and studies on epigenetics, gene expression and genomic profiles have brought to light several molecular subtypes with different clinical behavior [4-8]. On the basis of these findings, it can be hypothesized that the study of chromosomal instability in terms of gene copy number variations could help to identify subtypes of patients with different risk of progression and local recurrence [6,9].

In the present study we focused our attention on copy number changes in a panel of 24 oncogenes (MDM4, MYCN, ALK, PDGFRA, KIT, KDR, DHFR, EGFR, MET, SMO, FGFR1, MYC, ABL1, RET, CCND1, CCND2, CDK4, MDM2, AURKB, ERBB2, TOP2A, AURKA, AR and BRAF) known to be amplified in solid tumors and detected in DNA extracted from paraffin-embedded tissue of non muscle invasive bladder cancer. Our first aim was to identify some of these genes as recurrent predictive markers. Although several of these oncogenes, e.g., MDM2, AURKA, MYC, HER2, CCND1 and $M D M 4$, are known to be frequently amplified in bladder tumors of different grade and stage [10-14], their role as predictive markers in NMIBC has yet to be demonstrated. We chose the highly sensitive multiplex ligation probe amplification (MLPA) technique as it requires a low amount of DNA and is capable of analyzing several genes simultaneously [15]. 


\section{Results and Discussion}

\subsection{Results}

MLPA analysis was feasible for all 43 patients. The $A R$ gene was excluded from the analysis because it was not evaluable in paraffin-embedded tissues. Gain frequencies in the overall case series varied from 0.46 for MDM4 to 0.02 for KDR. Eight genes were not amplified (Table 1).

Table 1. Gain frequencies of each gene in the overall case series and in non recurrent and recurrent tumors.

\begin{tabular}{|c|c|c|c|c|}
\hline Gene & $\begin{array}{c}\text { Overall Series } \\
(43 \text { Cases }) \\
\end{array}$ & $\begin{array}{c}\text { Non Recurrent Tumors } \\
(20 \text { Cases })\end{array}$ & $\begin{array}{c}\text { Recurrent Tumors } \\
\text { (23 Cases) }\end{array}$ & $p$ Value * \\
\hline \multirow{2}{*}{$M D M 4$} & $20 / 43$ & $13 / 20$ & $7 / 23$ & \multirow[b]{2}{*}{0.023} \\
\hline & 0.46 & 0.65 & 0.3 & \\
\hline \multirow{2}{*}{$M E T$} & $15 / 43$ & $10 / 20$ & $5 / 23$ & \multirow[b]{2}{*}{0.052} \\
\hline & 0.35 & 0.5 & 0.22 & \\
\hline \multirow{2}{*}{$C D K 4$} & $12 / 43$ & $7 / 20$ & $5 / 23$ & \multirow{2}{*}{ NS } \\
\hline & 0.28 & 0.35 & 0.22 & \\
\hline \multirow{2}{*}{$M Y C$} & $12 / 43$ & $8 / 20$ & $4 / 23$ & \multirow{2}{*}{ NS } \\
\hline & 0.28 & 0.4 & 0.17 & \\
\hline \multirow{2}{*}{$T O P 2 A$} & $12 / 43$ & $8 / 20$ & $4 / 23$ & \multirow{2}{*}{ NS } \\
\hline & 0.27 & 0.4 & 0.17 & \\
\hline \multirow{2}{*}{$A U R K A$} & $11 / 43$ & $5 / 20$ & $6 / 23$ & \multirow{2}{*}{ NS } \\
\hline & 0.26 & 0.25 & 0.26 & \\
\hline \multirow{2}{*}{$E R B B 2$} & $9 / 43$ & $2 / 20$ & $7 / 23$ & \multirow{2}{*}{ NS } \\
\hline & 0.21 & 0.10 & 0.30 & \\
\hline \multirow{2}{*}{$M D M 2$} & $8 / 43$ & $6 / 20$ & $2 / 23$ & \multirow{2}{*}{ NS } \\
\hline & 0.19 & 0.3 & 0.09 & \\
\hline \multirow{2}{*}{$C C N D 1$} & $6 / 43$ & $4 / 20$ & $2 / 23$ & \multirow{2}{*}{ NS } \\
\hline & 0.14 & 0.2 & 0.09 & \\
\hline \multirow{2}{*}{$B R A F$} & $6 / 43$ & $3 / 20$ & $3 / 23$ & \multirow{2}{*}{ NS } \\
\hline & 0.14 & 0.15 & 0.13 & \\
\hline \multirow{2}{*}{ DHFR } & $5 / 43$ & $3 / 20$ & $2 / 23$ & \multirow{2}{*}{ NS } \\
\hline & 0.12 & 0.15 & 0.09 & \\
\hline \multirow{2}{*}{$F G F R$} & $4 / 43$ & $2 / 20$ & $2 / 23$ & \multirow{2}{*}{ NS } \\
\hline & 0.09 & 0.01 & 0.09 & \\
\hline \multirow{2}{*}{$C C N D 2$} & $4 / 43$ & $1 / 20$ & $3 / 23$ & \multirow{2}{*}{ NS } \\
\hline & 0.09 & 0.05 & 0.13 & \\
\hline \multirow{2}{*}{ KIT } & $3 / 43$ & $2 / 20$ & $1 / 23$ & \multirow{2}{*}{ NS } \\
\hline & 0.07 & 0.1 & 0.04 & \\
\hline \multirow{2}{*}{$K D R$} & $1 / 43$ & $0 / 20$ & $1 / 23$ & NS \\
\hline & 0.02 & 0 & 0.04 & NS \\
\hline$M Y C N$ & $0 / 43$ & $0 / 20$ & $0 / 23$ & NS \\
\hline$M Y C N$ & 0 & 0 & 0 & NS \\
\hline$A I K$ & $0 / 43$ & $0 / 20$ & $0 / 23$ & NS \\
\hline$A L \Lambda$ & 0 & 0 & 0 & NS \\
\hline
\end{tabular}


Table 1. Cont.

\begin{tabular}{|c|c|c|c|c|}
\hline Gene & $\begin{array}{l}\text { Overall Series } \\
\text { (43 Cases) }\end{array}$ & $\begin{array}{c}\text { Non Recurrent Tumors } \\
\text { (20 Cases) }\end{array}$ & $\begin{array}{l}\text { Recurrent Tumors } \\
\text { (23 Cases) }\end{array}$ & $p$ Value * \\
\hline \multirow{2}{*}{ PDGFR } & $0 / 43$ & $0 / 20$ & $0 / 23$ & \multirow{2}{*}{ NS } \\
\hline & 0 & 0 & 0 & \\
\hline \multirow{2}{*}{$E G F R$} & $0 / 40$ & $0 / 20$ & $0 / 23$ & \multirow{2}{*}{ NS } \\
\hline & 0 & 0 & 0 & \\
\hline \multirow{2}{*}{$A B L$} & $0 / 43$ & $0 / 20$ & $0 / 23$ & \multirow{2}{*}{ NS } \\
\hline & 0 & 0 & 0 & \\
\hline \multirow{2}{*}{$R E T$} & $0 / 43$ & $0 / 20$ & $0 / 23$ & \multirow{2}{*}{ NS } \\
\hline & 0 & 0 & 0 & \\
\hline \multirow{2}{*}{$A U R K B$} & $0 / 43$ & $0 / 20$ & $0 / 23$ & \multirow{2}{*}{ NS } \\
\hline & 0 & 0 & 0 & \\
\hline \multirow{2}{*}{$S M O$} & $0 / 43$ & $0 / 20$ & $0 / 23$ & \multirow{2}{*}{ NS } \\
\hline & 0 & 0 & 0 & \\
\hline
\end{tabular}

* Difference in gain frequencies between non recurrent and recurrent tumors (Fisher's exact test); NS, not significant.

A significant difference in the gain frequencies between non recurrent and recurrent tumors was observed for MDM4 (0.65 vs. 0.3; $p=0.023)$ (Table 1; Figure 1). No statistically significant association was observed between the copy number variations of all 23 genes analyzed and stage or grade. However, results for CCND1 were suggestive of a correlation with stage ( $p=0.057$, data not shown).

A median recurrence-free survival (RFS) of 64 months (95\% CI, 20-NR) was observed for the overall case series, with a median follow up of 86 months. Kaplan-Meier analysis of RFS was performed considering the copy number variations of MDM4. Five-year RFS was 70\% (95\% CI, 45.1-82.3) in patients carrying amplified MDM4 compared to 37.1\% (95\% CI, 17.8-56.6) in those with normal copy number (log-rank test $p=0.041$ ) (Figure 2). MDM4 amplification was not correlated with tumor grade, because the same distribution was observed between amplified and diploid cases. In particular, $5(25 \%)$ of the 20 patients with MDM4 amplification and 8 (36\%) of the 22 patients with no MDM4 amplification had high-grade tumors.

Figure 1. Gain frequencies in non recurrent $v s$. recurrent tumors.

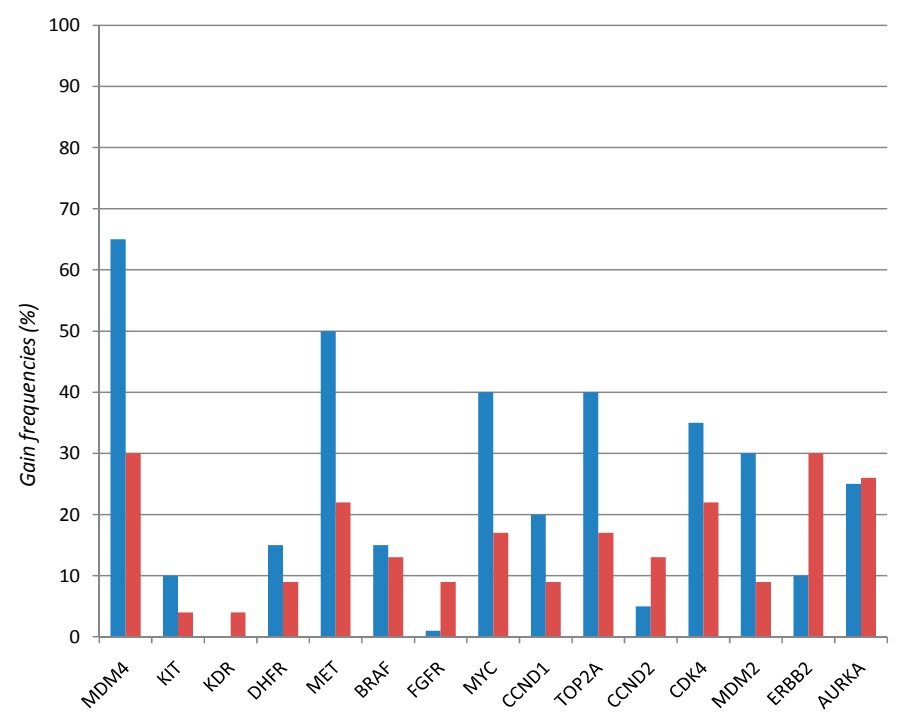


Figure 2. Recurrence-Free Survival (RFS)-Kaplan-Meier curves for MDM4. G, gain; N, normal.

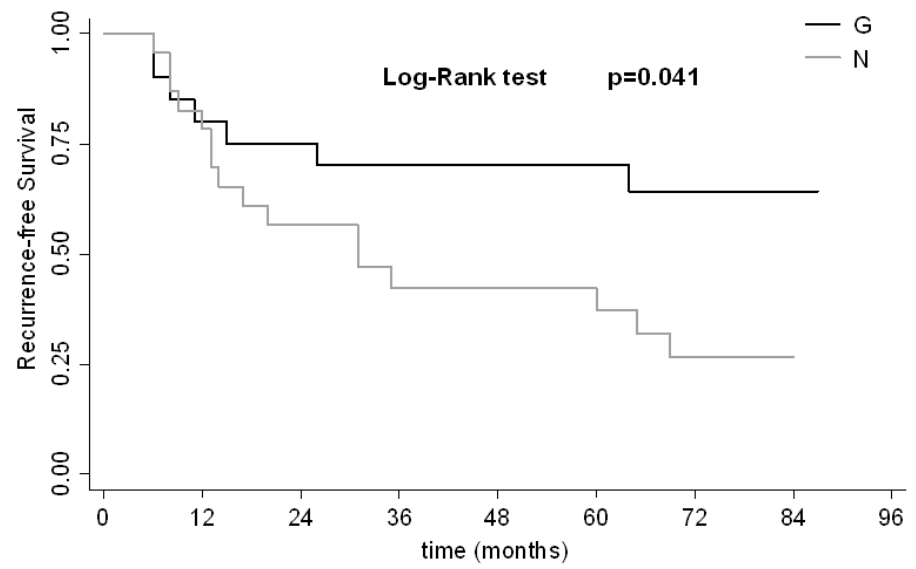

We considered 5 variables in the Cox regression analysis: age, stage, grade, MDM4. In the univariate model, age and MDM4 CNV were found to be predictive of RFS (Table 2). In particular, patients under 70 years of age showed a greater risk of recurrence than older ones (raw hazard ratio $=3.023$ ) (95\% CI, 1.301-7.026). This result was confirmed in multivariate analysis, revealing an adjusted hazard ratio of $3.318(1.420-7.753 ; p=0.006)$. In univariate analysis, patients with a normal MDM4 copy number had a higher risk of recurrence compared to those with amplified MDM4 (raw hazard ratio $=2.447)(95 \% \mathrm{CI}, 1.000-5.987 ; p=0.05)$. This risk was also confirmed in multivariate analysis (adjusted hazard ratio $=2.745)(95 \% \mathrm{CI}, 1.114-6.766 ; p=0.028)($ Table 2$)$.

Only 4 patients had disease progression, one of which showed amplified MDM4.

Table 2. Univariate and multivariate analyses for recurrence free survival.

\begin{tabular}{cccccc}
\hline Variables & Categories & Raw HR (95\% CI) & $\boldsymbol{p}$ & Adjusted HR (95\% CI) & $\boldsymbol{p}$ \\
\hline Age, years & $<70$ vs. $\geq 70$ & $3.023(1.301-7.026)$ & 0.010 & $3.318(1.420-7.753)$ & 0.006 \\
Stage & T1 vs. Ta & $1.472(0.605-3.580)$ & 0.394 & - & - \\
Grade & High vs. Low & $1.369(0.573-3.269)$ & 0.479 & - & - \\
MDM4 & N vs. G & $2.447(1.000-5.987)$ & 0.05 & $2.745(1.114-6.766)$ & 0.028 \\
\hline
\end{tabular}

\subsection{Discussion}

We evaluated a panel of 24 chromosomal aberrations in paraffin-embedded primary NMIBC tissue for their potential to identify patients at high risk of recurrence. An MLPA technique was used that was capable of simultaneously analyzing the entire panel of 24 oncogene copy number variations. A statistically significant association was observed between MDM4 amplification and a lower risk of NMIBC recurrence.

The MDM4 gene, located on 1q32.1, encodes a nuclear protein that contains a p53-binding domain which shows a structural similarity to the same domain in MDM2. MDM4 protein acts as an oncogene, inhibiting p53 activity by binding its transcriptional activation domain [16,17]. p53 has been shown to play an important role in bladder cancer tumorigenesis and numerous studies have demonstrated that the gene is often mutated [18] and its expression frequently altered, possibly as a result of altered MDM2 or MDM4 genes or proteins [19,20]. 
In their study of patients with high-grade and -stage bladder cancer, Veerakumarasivam and coworkers observed that MDM4 gene amplification was mutually exclusive of p53 mutation. In our case series, MDM4 gain was seen in $65 \%$ of non recurrent NMIBC and in $30 \%$ of recurrent cases. It can thus be hypothesized that the p53 pathway is regulated in a different way in the two categories, i.e., via MDM4 amplification in non recurrent patients and via $p 53$ mutation in recurrent cases. This is in agreement with the results from a study conducted by George et al. in 2007 on a series of mainly invasive bladder cancers [21] in which a positive correlation was identified between mutated $p 53$ and a high risk of recurrence in patients with bladder cancer. A more comprehensive study of MDM4 amplification and p53 mutations and their correlation with disease recurrence in NMIBC is needed to confirm our hypothesis.

The primary objective of our study was to verify any association between copy number variations of selected genes and the risk of local recurrence in NMIBC. Of the 24 genes analyzed, the only statistically significant association was found with $M D M 4$. Some other important genes (MET, MYC, TOP2A, AURKA, ERBB2, MDM2, CCND1, BRAF) were frequently amplified in the overall case series, in agreement with the literature data available on gene copy number alterations in bladder cancer [10-14]. These amplified oncogenes were not correlated with stage or grade but could represent putative therapeutic targets for NMIBC. Indeed, some of the genes, e.g., ERBB2 and MET, are already used as targets for known drugs [22,23].

Bladder cancer is a genetically heterogeneous disease [24] and it would be useful to further our knowledge about gene expression and copy number variations so that new therapeutic targets can be identified and used to tailor treatment.

The present study has some limitations in that it recruited a small number of patients and only used one technique (MLPA) to evaluate copy number variations. The results obtained must now be confirmed in a larger case series and perhaps using a second technique, e.g., real time PCR. A prospective study will be performed to validate our findings.

\section{Experimental Section}

\subsection{Case Series (Retrospective Cohort Study)}

Tissue samples from 43 patients (39 males, 4 females) who underwent transurethral resection of primary bladder cancer in the Department of Urology of Morgagni-Pierantoni Hospital in Forlì between 1997 and 2006 were used for the study. All samples were retrieved from the archives of the Pathology Unit of the same hospital. All patients were in agreement with our biobank and gave written informed consent for their biological material to be used for research purposes (protocol number: 2192/2013, approved by IRST Ethics Committee on 9 May 2013). Median patient age was 72 years (range 39-89): 18 were $<70$ years and $25 \geq 70$ years. The final diagnosis, based on 2004 World Health Organization criteria, was low grade non muscle invasive bladder cancer (NMIBC) in 28 patients and high grade NMIBC in 13 patients. At a median follow up of 5 years, 20 patients were still disease-free and 23 had experienced one or more episodes of local recurrence. Patient characteristics are summarized in Table 3. 
Table 3. Case series.

\begin{tabular}{ccc}
\hline Clinical and Pathological & \multicolumn{2}{c}{ Patients $(\boldsymbol{n}=\mathbf{4 3})$} \\
\cline { 2 - 3 } Characteristics & Non Relapsed & Relapsed \\
\hline Sex & 18 & 21 \\
Male & 2 & 2 \\
Female & & \\
Age, years & 4 & 14 \\
$<70$ & 16 & 9 \\
$\geq 70$ & & \\
Grade & 5 & 8 \\
High & 14 & 14 \\
Low & & 16 \\
Stage & 16 & 7 \\
Ta & 4 & 13 \\
T1 & & 9 \\
\hline Number of tumors & 14 &
\end{tabular}

\subsection{Macrodissection and DNA Isolation}

Five-micrometer-thick sections were obtained from each paraffin-embedded block and evaluated by hematoxylin-eosin staining. DNA was then isolated from macrodissected cancer tissue only. Genomic DNA was purified using QIAmp DNA FFPE Tissue (Qiagen, Milan, Italy), according to the manufacturer's instructions. DNA was also isolated from peripheral blood samples from 4 healthy donors using Qiamp DNA Mini Kit (Qiagen, Milan, Italy), according to the manufacturer's instructions, to be used as a control in further analysis.

\subsection{Multiplex Ligation Probe Amplification (MLPA) Analysis}

MLPA was performed using at least $50 \mathrm{ng}$ of genomic DNA dissolved in $1 \times$ TE buffer (Promega, Madison, WI, USA). The amplification status of 24 oncogenes (MDM4, MYCN, ALK, PDGFRA, KIT, KDR, DHFR, EGFR, MET, SMO, FGFR1, MYC, ABL1, RET, CCND1, CCND2, CDK4, MDM2, AURKB, ERBB2, TOP2A, AURKA, AR, BRAF) and BRAF V600E mutation were analyzed using P175-A1 kit (MRC-Holland, Amsterdam, The Netherlands) (Table 4). Two different probes that recognize two different sites were used for all but the CCND2 gene, for which three probes were used.

In brief, DNA was denatured $\left(10 \mathrm{~min}\right.$ at $\left.98{ }^{\circ} \mathrm{C}\right)$ and cooled at $25^{\circ} \mathrm{C}$, after which the probe mix was added to the samples and hybridization was performed by incubating at $60{ }^{\circ} \mathrm{C}$ for $16-18 \mathrm{~h}$.

A mix composed of ligase- 65 buffer, ligase- 65 enzyme and water was added and samples were then incubated at $54{ }^{\circ} \mathrm{C}$ for $15 \mathrm{~min}$. At the end of the ligation reaction, samples were amplified by adding a mix of PCR buffer, dNTPs and Taq polymerase. The PCR reaction was performed under the following conditions: 37 cycles at $95{ }^{\circ} \mathrm{C}$ for $30 \mathrm{~s}, 60{ }^{\circ} \mathrm{C}$ for $30 \mathrm{~s}$ and $72{ }^{\circ} \mathrm{C}$ for $60 \mathrm{~s}$. The final incubation was performed at $73{ }^{\circ} \mathrm{C}$ for $20 \mathrm{~min}$. 
Table 4. Summary of gene function and chromosomal localization.

\begin{tabular}{clcc}
\hline Gene & \multicolumn{1}{c}{ Function } & Chromosomal Localization & Exons \\
\hline$M D M 4$ & Cell cycle and apoptosis & $1 \mathrm{q} 32.1$ & 2,8 \\
$M Y C N$ & Transcription factor & $2 \mathrm{p} .24$ & 3 \\
$A L K$ & Receptor tyrosine kinase & $2 \mathrm{p} 23.2$ & 4,6 \\
$P D G F R A$ & Cell proliferation and survival & $4 \mathrm{q} 12$ & 3,22 \\
$K I T$ & Cell proliferation and survival & $4 \mathrm{q} 12$ & 2,20 \\
$K D R$ & Regulation of angiogenesis & $4 \mathrm{q} 12$ & 14,19 \\
$D H F R$ & Cell growth and proliferation & $5 \mathrm{q} 14.1$ & 1,2 \\
$E G F R$ & Cell proliferation & $7 \mathrm{P} 11.2$ & 8,22 \\
$M E T$ & Tumor growth, angiogenesis and metastasis & $7 \mathrm{q} 31$ & 4,10 \\
$S M O$ & Maintenance of tissue homeostasis & $7 \mathrm{q} 32.1$ & 4,12 \\
$F G F R$ & Cell proliferation & $8 \mathrm{p} 11.2$ & 8,14 \\
$M Y C$ & Regulation of gene transcription & $8 \mathrm{q} 24.1$ & 3 \\
$A B L$ & Cell growth and survival & $9 \mathrm{q} 34.1$ & 1,12 \\
$R E T$ & Cell proliferation, cell migration and & $10 \mathrm{q} 11.2$ & 8,14 \\
$C C N D 1$ & Cell differentiation & $11 \mathrm{q} 13$ & $2,3,5$ \\
$T O P 2 A$ & DNA replication, transcription and repair & $17 \mathrm{q} 21.2$ & 7,33 \\
$C C N D 2$ & Cell-cycle regulation & $12 \mathrm{p} 13.3$ & 1,5 \\
$C D K 4$ & Cell-cycle regulation & $12 \mathrm{q} 14$ & 3,8 \\
$M D M 2$ & Cell cycle and apoptosis & $12 \mathrm{q} 14.3$ & 4,5 \\
$E R B B 2$ & Transcriptional regulation & $17 \mathrm{q} 12$ & 7,29 \\
$A U R K B$ & Regulator of mitosis & $17 \mathrm{p} 13.1$ & 4,5 \\
$A U R K A$ & Regulator of mitosis & $20 \mathrm{q} 13.2$ & 8,10 \\
$A R$ & Androgen receptor & Xq12 & 9 \\
\hline & & & \\
\hline
\end{tabular}

Amplification products were analyzed by ABI-3130 genetic Analyzer (Applied Biosystems, Cambridge, UK) and 4 reference blood samples were used as controls in each experiment. Electropherograms (Figure 3) were analyzed using Gene Mapper software (Applied Biosystems) and the peak areas of each probe were exported to a self-made spreadsheet. The analysis was performed using Coffalyser software [25], in accordance with the manufacturer's instructions, and a ratio for each probe was obtained. The final result for each gene was considered as the average of the different probe ratios, which were divided into three categories: "normal" (results between 0.7 and 1.3), "gain" (results $>1.3$ ) and "deletion" (results $<0.7$ ). The $A R$ gene was excluded from the analysis because it was not evaluable in paraffin-embedded tissues. 
Figure 3. Electropherogram of a control sample ( $x$-axis: fragments size (nt); $y$-axis: dye signal).

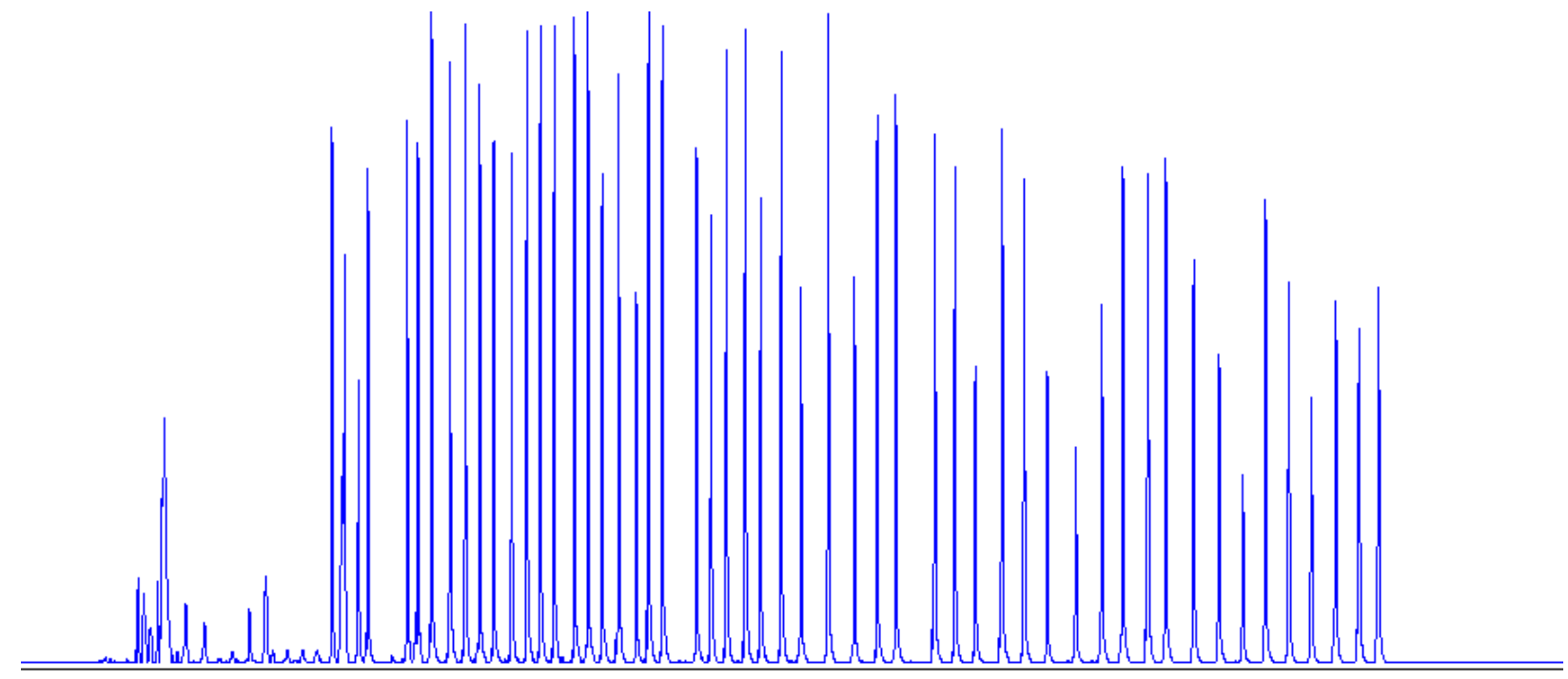

\subsection{Statistical Analysis}

Fisher's exact test was used to compare the frequency of gene gain in the two subgroups (non recurrent tumors $v s$. recurrent tumors). Due to explorative intent of the study, no corrections were made for multiple testing. RFS was defined as the time between the first diagnosis of primary bladder cancer and the date of the first recurrence. Patients who were still disease-free at database closure were censored at the last follow up. All patients were followed up for at least 5 years.

Cumulative RFS probabilities were estimated using the Kaplan-Meier method and copy number variations of MDM4 gene were compared using the log-rank test. A Cox regression model was used to estimate RFS hazard ratios (HR) and 95\% confidence intervals (CI). The multivariate Cox model included factors that proved significant in the univariate model. All $p$-values were two-sided and a $p<0.05$ was considered statistically significant. Statistical analyses were performed using SAS 9.3 software (SAS Institute, Cary, NC, USA).

\section{Conclusions}

The present study identified a statistically significant association between MDM4 amplification and a reduced risk of recurrence of NMIBC. We also observed the frequent amplification of other important genes such as $M E T$ and $E R B B 2$, which could, in future, represent important targets for known drugs. Our findings are key to enhancing the use of personalized medicine in bladder cancer and now require confirmation in larger, prospective studies.

\section{Acknowledgments}

The authors thank Ursula Elbling for editing the manuscript. 


\section{Author Contributions}

Samanta Salvi carried out the molecular studies and drafted the manuscript. Daniele Calistri participated in the study conception and design. Giorgia Gurioli performed the molecular analyses. Luigi Serra and Roberta Gunelli were responsible for patient enrolment and data collection. Elisa Carretta performed the statistical analyses. Wainer Zoli revised the manuscript for important intellectual content. Valentina Casadio participated in the study conception and revised the manuscript for important intellectual content.

\section{Conflicts of Interest}

The authors declare no conflict of interest.

\section{References}

1. Jemal, A.; Bray, F.; Center, M.M.; Ferlay, J.; Ward, E.; Forman, D. Global cancer statistics. CA Cancer J. Clin. 2011, 61, 69-90.

2. Van Rhijn, B.W.; Burger, M.; Lotan, Y.; Solsona, E.; Stief, C.G.; Sylvester, R.J.; Witjes, J.A.; Zlotta, A.R. Recurrence and progression of disease in non-muscle-invasive bladder cancer: From epidemiology to treatment strategy. Eur. Urol. 2009, 56, 430-442.

3. Bryan, R.T.; Collins, S.I.; Daykin, M.C.; Zeegers, M.P.; Cheng, K.K.; Wallace, D.M.; Sole, G.M. Mechanisms of recurrence of Ta/T1 bladder cancer. Ann. R. Coll. Surg. Engl. 2010, 92, 519-524.

4. Casadio, V.; Molinari, C.; Calistri, D.; Tebaldi, M.; Gunelli, R.; Serra, L.; Falcini, F.; Zingaretti, C.; Silvestrini, R.; Amadori, D.; et al. DNA methylation profiles as predictors of recurrence in non muscle invasive bladder cancer: An MS-MLPA approach. J. Exp. Clin. Cancer Res. 2013, 32, 94.

5. Lindgren, D.; Gudjonsson, S.; Jee, K.J.; Liedberg, F.; Aits, S.; Andersson, A.; Chebil, G.; Borg, A.; Knuutila, S.; Fioretos, T.; et al. Recurrent and multiple bladder tumors show conserved expression profiles. BMC Cancer 2008, 8, 183.

6. Lindgren, D.; Sjödahl, G.; Lauss, M.; Staaf, J.; Chebil, G.; Lövgren, K.; Gudjonsson, S.; Liedberg, F.; Patschan, O.; Månsson, W.; et al. Integrated genomic and gene expression profiling identifies two majorgenomic circuits in urothelial carcinoma. PLoS One 2012, 7, e38863.

7. Yamamoto, Y.; Matsuyama, H.; Kawauchi, S.; Furuya, T.; Liu, X.P.; Ikemoto, K.; Oga, A.; Naito, K.; Sasaki, K. Biological characteristics in bladder cancer depend on the type of genetic instability. Clin. Cancer Res. 2006, 12, 2752-2758.

8. Hurst, C.D.; Platt, F.M.; Taylor, C.F.; Knowles, M.A. Novel tumor subgroups of urothelial carcinoma of the bladder defined by integrated genomic analysis. Clin. Cancer Res. 2012, 18, 5865-5877.

9. Höglund, M.; Säll, T.; Heim, S.; Mitelman, F.; Mandahl, N.; Fadl-Elmula, I. Identification of cytogenetic subgroups and karyotypic pathways in transitional cell carcinoma. Cancer Res. 2001, $61,8241-8246$.

10. Watters, A.D.; Latif, Z.; Forsyth, A.; Dunn, I.; Underwood, M.A.; Grigor, K.M.; Bartlett, J.M. Genetic aberrations of c-myc and CCND1 in the development of invasive bladder cancer. Br. J. Cancer 2002, 87, 654-658. 
11. Veerakumarasivam, A.; Scott, H.E.; Chin, S.F.; Warren, A.; Wallard, M.J.; Grimmer, D.; Ichimura, K.; Caldas, C.; Collins, V.P.; Neal, D.E.; et al. High-resolution array-based comparative genomic hybridization of bladder cancers identifies mouse double minute 4 (MDM4) as an amplification target exclusive of MDM2 and TP53. Clin. Cancer Res. 2008, 14, 2527-2534.

12. Simon, R.; Struckmann, K.; Schraml, P.; Wagner, U.; Forster, T.; Moch, H.; Fijan, A.; Bruderer, J.; Wilber, K.; Mihatsch, M.J.; et al. Amplification pattern of 12q13-q15 genes (MDM2, CDK4, GLI) in urinary bladder cancer. Oncogene 2002, 21, 2476-2483.

13. Park, H.S.; Park, W.S.; Bondaruk, J.; Tanaka, N.; Katayama, H.; Lee, S.; Spiess, P.E.; Steinberg, J.R.; Wang, Z.; Katz, R.L.; et al. Quantitation of aurora kinase a gene copy number in urine sediments and bladder cancer detection. J. Natl. Cancer Inst. 2008, 100, 1401-1411.

14. The Cancer Genome Atlas Research Network. Comprehensive molecular characterization of urothelial bladder carcinoma. Nature 2014, 507, 315-322.

15. Schouten, J.P.; McElgunn, C.J.; Waaijer, R.; Zwijnenburg, D.; Diepvens, F.; Pals, G. Relative quantification of 40 nucleic acid sequences by multiplex ligation-dependent probe amplification. Nucleic Acids. Res. 2002, 30, e57.

16. Toledo, F.; Wahl, G.M. MDM2 and MDM4: p53 regulators as targets in anticancer therapy. Int. J. Biochem. Cell. Biol. 2007, 39, 1476-1482.

17. Mancini, F.; di Conza, G.; Moretti, F. MDM4 (MDMX) and its transcript variants. Curr. Genomics 2009, 10, 42-50.

18. Bakkar, A.A.; Wallerand, H.; Radvanyi, F.; Lahaye, J.B.; Pissard, S.; Lecerf, L.; Kouyoumdjian, J.C.; Abbou, C.C.; Pairon, J.C.; Jaurand, M.C.; et al. FGFR3 and TP53 gene mutations define two distinct pathways in urothelial cell carcinoma of the bladder. Cancer Res. 2003, 63, 8108-8112.

19. Wang, L.; Feng, C.; Ding, G.; Ding, Q.; Zhou, Z.; Jiang, H.; Wu, Z. Ki67 and TP53 expressions predict recurrence of non-muscle-invasive bladder cancer. Tumour Biol. 2014, 35, 2989-2995.

20. Papadogianni, D.; Soulitzis, N.; Delakas, D.; Spandidos, D.A. Expression of p53 family genes in urinary bladder cancer: Correlation with disease aggressiveness and recurrence. Tumour Biol. 2014, 35, 2481-2489.

21. George, B.; Datar, R.H.; Wu, L.; Cai, J.; Patten, N.; Beil, S.J.; Groshen, S.; Stein, J.; Skinner, D.; Jones, P.A.; et al. p53 gene and protein status: The role of $p 53$ alterations in predicting outcome in patients with bladder cancer. J. Clin. Oncol. 2007, 25, 5352-5358.

22. Marín, A.P.; Arranz, E.E.; Sánchez, A.R.; Auñón, P.Z.; Barón, M.G. Role of anti-Her-2 therapy in bladder carcinoma. J. Cancer Res. Clin. Oncol. 2010, 136, 1915-1920.

23. Sharma, N.; Adjei, A.A. In the clinic: Ongoing clinical trials evaluating c-MET-inhibiting drugs. Ther. Adv. Med. Oncol. 2011, 3, S37-S50.

24. Iyer, G.; Al-Ahmadie, H.; Schultz, N.; Hanrahan, A.J.; Ostrovnaya, I.; Balar, A.V.; Kim, P.H.; Lin, O.; Weinhold, N.; Sander, C.; et al. Prevalence and co-occurrence of actionable genomic alterations in high-grade bladder cancer. J. Clin. Oncol. 2013, 31, 3133-3140.

25. MRC-Holland. Available online: https://www.mlpa.com (accessed on 20 March 2014).

(C) 2014 by the authors; licensee MDPI, Basel, Switzerland. This article is an open access article distributed under the terms and conditions of the Creative Commons Attribution license (http://creativecommons.org/licenses/by/3.0/). 